\title{
IUMRS-ICAM'99 Presents Symposia and Forums on Advanced Materials
}

\begin{abstract}
The Chinese Materials Research Society (C-MRS) hosted the International Conference on Advanced Materials (ICAM) on behalf of the International Union of Materials Research Societies (IUMRS) in Beijing, from June 13 to 18,1999 . The IUMRS sponsors ICAM in odd-numbered years, and the International Conference on Electronic Materials (ICEM) in evennumbered years, thereby providing a continually renewable platform for the dissemination of data on materials advances and results in these areas.

The IUMRS-ICAM'99 Meeting was convened in the Beijing International Conference Center, about eight miles north of the city center. The conference comprised 36 symposia, and featured four IUMRS-sponsored forums to encourage open discussion on materials-related topics. More than 1,600 delegates from 40 countries or independent regions attended the meeting, making it the largest and most multinational ICAM meeting to date. About half of the oral presentations were made by delegates who arrived from out-
\end{abstract}

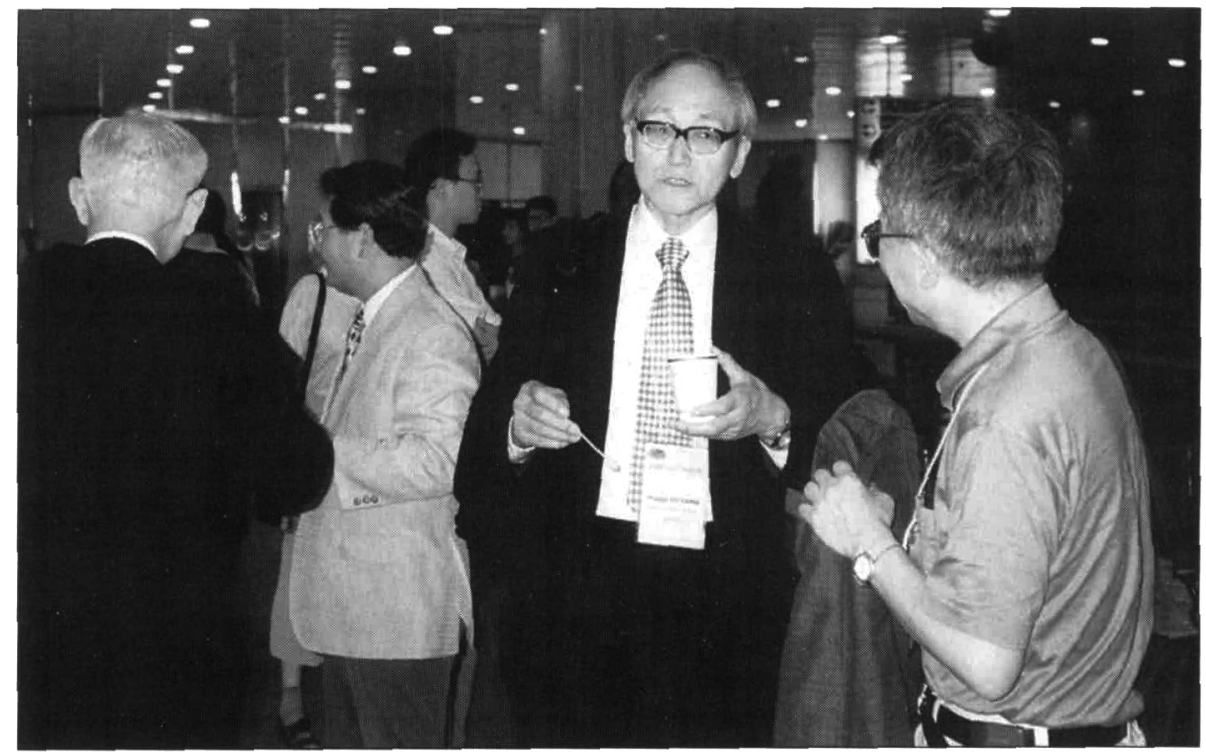

M. Doyama of Nishi-Tokyo University in Japan and 1997 President of the International Union of Materials Research Societies (IUMRS) takes the opportunity to talk with attendees at the IUMRSInternational Conference on Advanced Materials (ICAM) hosted by Chinese-MRS in Beijing on June 13-18, 1999 .

\section{Young Research Awards Presented}

Prizes were awarded for superior presentations by younger authors in the poster sessions. Award recipients are Wanmin Yang, L. Zhou, Y. Feng, P.X. Zhang, J. R. Wang, C.P. Zhang, Z.H. Du, F.Y. Wang, Z.M. Yu, X.D. Tang, and X.Z. Wu (Northwest Institute for Nonferrous Metal Research, $\mathrm{Xi}^{\prime} \mathrm{An}, \mathrm{China}$ ), "Analysis of the Morphology and Chemical Components at the Growth Front of YBCO Bulk Materials" (B42); Fengying Li, Yuliang Li, Yinglin Song, and Daoben Zhu (Institute of Chemistry, Chinese Academy of Sciences, Beijing, China), "Synthesis and Optical Properties of Polycarbonates Containing Fullerene Derivative" (C46); Guangyong Zhou, Jianru Han, Shujun Zhang, Zhenxiang Cheng, and Huanchu Chen (State Key Lab of Crystal Materials, Shandong University, Jinan, China), "Synthesis, Growth and Characterization of a New Laser Upconversion Crystal $\mathrm{Ba}_{2} \mathrm{ErCl}_{7}$ " (L34); S.R.P. Silva (School of Electronic Engineering, University of Survey, Guildford, UK), "Amorphous Semiconductors for Cold Cathodes: A Route to Cheap, Large Area Flat Panel Displays" (P30); D.S. Mao, J. Zhao, W. Li, X. Wang, Y.H. Yu, X.H. Liu, Y.K. Zhu, Q. Li, and J.F. Xu (Ion Beam Laboratory, Shanghai Institute of Metallurgy, Chinese Academy of Sciences, Shanghai, China), "Electron Field Emission from HydrogenFree Amorphous Carbon Films under Annealing Conditions" (W20); D. Zhong, J.J. Moore, J. Disam, S. Thiel, and I. Dahan (Advanced Coating and Surface Engineering Laboratory, Colorado School of Mines, Colorado, USA), "Deposition and Characterization of $\mathrm{NiAl}$ and $\mathrm{Ni}-\mathrm{Al}-\mathrm{N}$ Thin Films from a NiAl Compound Target" (X28); Jun Zhang, Yanying Tan, Shuangming Li, Jianguo Li, and Hengzhi Fu (Northwestern Polytechnical University, Xian, China), "Frequency Effect on Electromagnetic Confinement and Shaping of Liquid Metal" (Y49); Y. Zhou, B. Zhou, X. Guo, and G. He (Institute of Metal Research, Chinese Academy of Sciences, Shenyang, China), "The Reversing Effect of Electropulsing on the Damage of 1045 Steel" (BB64); X. Cao, L. Feng, and X. Yi (Institute of Polymer Science and Materials, Zhejiang University, Hangzhou, China), "The Conductivity of Carbon Black/HDPE Composites Prepared by Filling Polymerization" (FF12); and J. Li, D. Liao, and S. Yip (Massachusetts Institute of Technology, Massachusetts, USA), "Nearly Exact Solution for Coupled Continuum/MD Fluid Simulation" (J554). side China, many of whom were returning Chinese. The host nation dominated in the poster sessions where special prizes were awarded for superior presentations by younger authors (see Sidebar). The location of the meeting in Beijing provided the ICAM attendees with many opportunities for sightseeing, with most visitors making trips to see the Great Wall and Summer Palace. The conference included an evening of musical entertainment in the Forbidden City, and a banquet in the Great Hall of the People, on Tiananmen Square. The ICAM attendees were treated with warmth, grace, and friendliness.

During the first three days, the morning sessions were devoted to a single plenary symposium, designated "Symposium AA," in which world-renowned experts presented review talks and attempted to predict future directions for their fields in the first decade of the new millennium. Nobel laureate Leo Esaki (IBM T.J. Watson Research Center) opened his keynote speech "Electron Wave Engineering" with a reference to the upcoming Conference at Tsukuba (November 17-19) (www.sft.gr.jp) for which the materials science keynote speaker, Eiichi Maruyama, has issued the statement, "The miniaturizing and enhancement of a number of electronic products linked closely to our daily lives, such as personal computers and cellular phones, have 
been supported by the development of new materials and devices. Materials science, the basis for all such advances, is enjoying new developments almost every day. Peculiar properties have been found in fullerenes and nanotubes, quantum wires in semiconductors, and other nanostructures."

Esaki continued by stating that science's greatest achievements are the atom theory, gene understanding, and computer development. He said that researchers have had to make the transition from observers to participants in order to create a synthetic environment. He said, "Creative failures

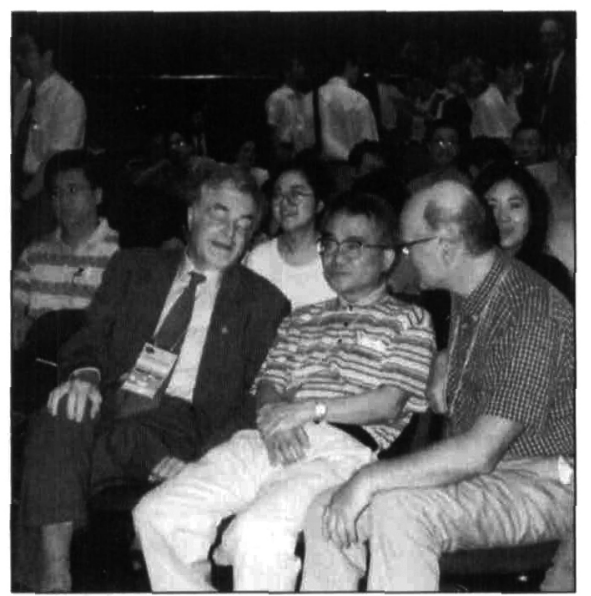

One of the plenary speakers Robert W. Cahn of Cambridge University (front row, left), converses with meeting attendees at IUMRS-ICAM'99 in Beijing. Cahn's presentation is published in the September 1999 issue of MRS Bulletin, page 3.

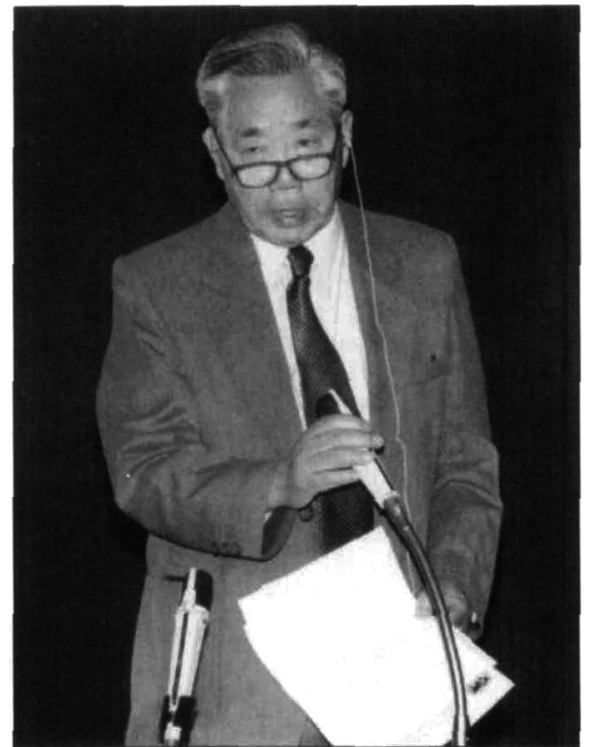

Heng-De Li is President of the International Union of Materials Research Societies (ILMRS) and of the Chinese-MRS (C-MRS), who hosted IUMRS-ICAM '99 in Beijing.

have helped in this development where chance has led to serendipity and to surprise." As an example, Esaki pointed to the work by Zener on the tunnel diode, which was wrong but caused others to look at the device.

Esaki had announced his diode and its understanding at the 1969 IEEE Electron Device Society Device Research Conference. He described it as a progression from quantum physics, through device fabrication, to materials science. Esaki said that a researcher has to move from a judicial mind to a creative mind and visit the future before anybody else and in doing so scientists must transcend race doctrine and creed.

Regular symposia consisted of a mixture of invited and contributed papers, and contributed posters. Topics receiving active attention included biomaterials, "spintronics," and environmental materials, which has become an important thrust of governmental funding in Japan, and is growing in importance in Europe.

The four forums addressed "The Role of Advanced Materials in Social and Economic Sustainable Development" (jointly sponsored with the European Academy of Sciences and Arts), "Global Networks on Materials Research and Development," "Materials Education," and the IMAAC (International Materials Assessment and Applications Center) Forum '99 (sponsored by the United Nations Industrial Development Organization). Presenters in the networking forum introduced the online Chinese Materials Bulletin (CHIMEB) (www.chimeb.edu.cn). This project was initiated by the younger members of C-MRS. This is a systematic and unified website containing a wide range of materials-related content, in addition to a job-search page that is attracting many users as job mobility grows in China. This well-ordered website is a focal point for materials-related information in China, and is an interesting contrast to the multitude of sites of variable content and quality elsewhere in the world.

ALEX KING

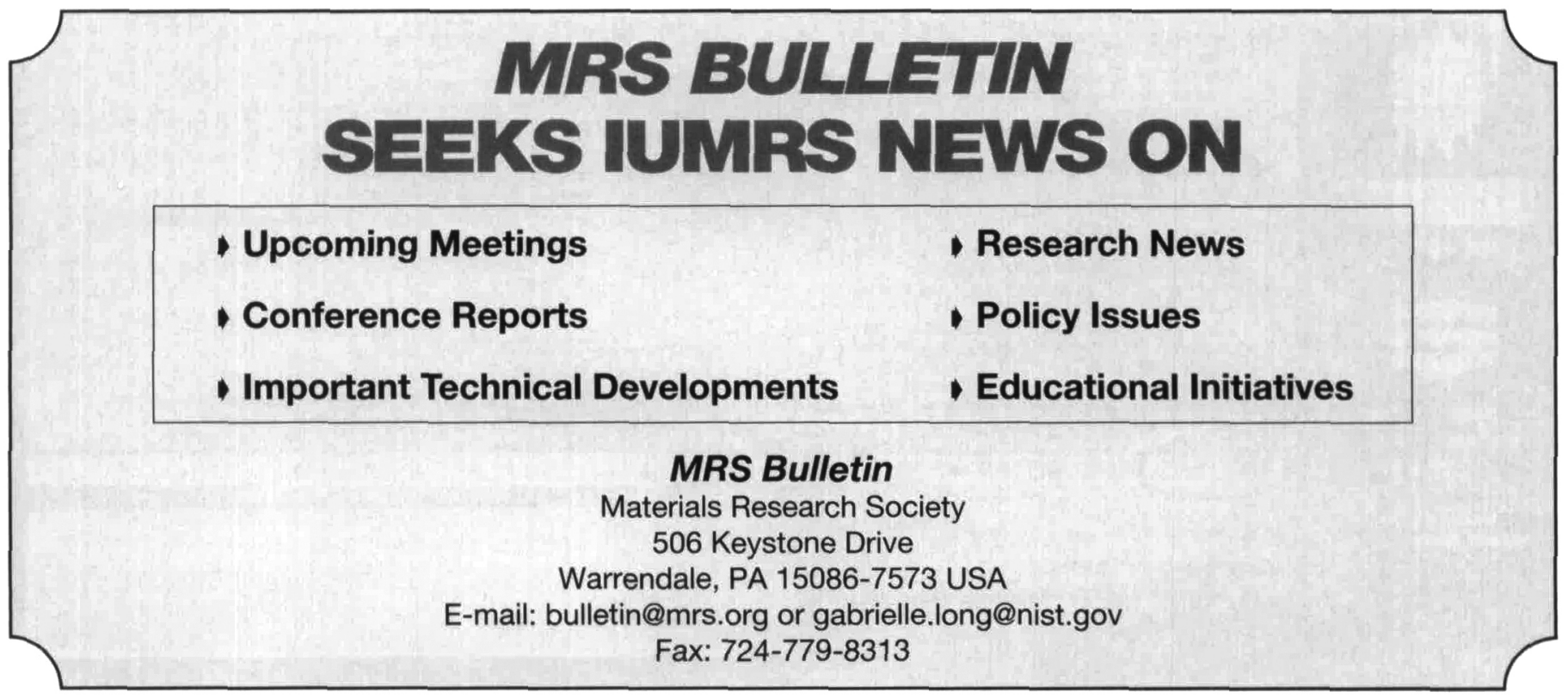

